\title{
Interocular transfer in pigeons of color discrimination but not motor response training
}

\author{
VICTOR J. STEVENS and WALDEN R. KIRSCH \\ Reed College, Portland, Oregon 97202
}

\begin{abstract}
Adult pigeons with one eye covered were trained to peck a response key using grain as a reinforcer. In subsequent tests, with the trained eye covered and the control eye open, the birds failed to peck the key. The subjects were then divided into two groups for a second experiment. The first group was trained on a single-key, peck/no-peck color discrimination task with the original control eye covered. When tested for interocular transfer of discrimination performance, these birds failed to respond at all. They were then trained to peck a blank response key with the training eye covered and the control eye open. Control-eye tests after this motor response training resulted in excellent transfer of color discrimination performance. The second group of subjects was trained to peck a blank key with first one eye covered and then the other, before monocular discrimination training was begun. These birds showed excellent transfer of discrimination performance during controleye tests. These results show that, at least in the operant paradigm, motor response training does not transfer interocularly and this lack of transfer may interfere with transfer of discrimination performance.
\end{abstract}

Since there is a complete decussation at the optic chiasma of birds, information from each eye is directly transmitted only to the contralateral optic lobe (Cowan, Adamson, \& Powell, 1961; Polyak, 1957). Therefore, when a bird has been trained on a visual discrimination with one eye covered, moving the cover to the trained eye and testing the untrained (control) eye provides a measure of transfer of conditioning between each half of the brain. This phenomenon is of particular interest since the avian brain lacks a corpus callosum.

Although there have been a number of experimental studies of interocular transfer, the environmental conditions which control its occurrence are not well understood. For many conditioning paradigms, birds resemble mammalian "split-brain" preparations and fail to show interocular transfer of discrimination performance; yet, in some situations they demonstrate transfer with little or no decrement in performance.

Lack of transfer has been evident in such diverse situations as visual cliff habituation (Zeier, 1970) and imprinting (P. H. Klopfer, 1973). In sharp contrast, transfer has been shown for peck avoidance training (Cherkin, 1970) and in a great number of operant conditioning studies. Most of the operant studies have been concerned with the question of mirrorimage reversal, which is often apparent during interocular transfer tests (e.g., Cheney \& Tam, 1972; Corballis \& Beale, 1970; Mello, 1967; Tieman,

We wish to thank Greg Eibel and Leah Kleinman for their technical assistance and Kathy Chambers and Allen Neuringer for their criticisms of an earlier draft of this report. Requests for reprints should be sent to Victor J. Stevens, Health Services Research Center, 4610 S.E. Belmont, Portland, Oregon 97215.
Tieman, Brody, \& Hamilton, 1974). When bilaterally symmetrical stimuli are used in the operant paradigm, transfer occurs with only a minimal decrease in discrimination accuracy (e.g., Catania, 1965; Mello, Ervin, \& Cobb, 1963). Only one of the dozens of studies using operant techniques has shown lack of transfer of visual discrimination performance. Green, Brecha, and Gazzaniga (1978) found that when pigeons were trained on a task in which visual signals indicated the appropriate spatial response (left key response vs, right), they were unable to perform above chance levels during transfer tests.

In an attempt to identify the variables controlling interocular transfer, Stevens and F. D. Klopfer (1977) tested the hypothesis that transfer of conditioning would fail to occur when all the relevant stimuli were presented unilaterally (to one eye), but that positive transfer would be seen if the UCS was presented bilaterally. Using a classical conditioning paradigm, they found no evidence of transfer when a looming object was the UCS and strong transfer when bilateral electrical shock was the UCS. Also consistent with their hypothesis, there was no transfer of habituation effects following repeated monocular presentation of conditioned aversive visual stimuli. However, when a loud noise (a bilaterally received stimulus) was used as the UCS, there was no evidence of interocular transfer of conditioning and the hypothesis had to be rejected.

The current study represents further efforts to determine the environmental variables controlling the occurrence of interocular transfer. Experiment 1 was begun when the discovery was made that birds with one eye covered (occluded) during training could not perform simple tasks such as turning 
circles or pecking a response key when the occluder was moved to the other eye. These findings were particularly surprising because they appeared to conflict with a great deal of previous work using operant conditioning techniques.

\section{EXPERIMENT 1}

In the pilot study, pigeons with one eye covered were hand-shaped to peck a response key by reinforcement of successive approximations. In the current experiment, an autoshaping procedure (Brown \& Jenkins, 1968; Hearst \& Jenkins, 1974) was used to control for possible experimentor bias effects.

\section{Method}

Subjects. The subjects were 12 experimentally naive, adult homing pigeons. For the duration of the study, they were housed in individual cages with continuous access to water and grit.

Apparatus. The experimental chamber was a $35 \times 29 \times 38 \mathrm{~cm}$ box with a single, transparent response key, $1.7 \mathrm{~cm}$ in diameter, centered on the rear wall $27 \mathrm{~cm}$ above the floor. When the key was illuminated, a blank wood panel was visible $.5 \mathrm{~cm}$ behind the key surface. A standard, automated grain hopper (Gerbrands) was positioned $10 \mathrm{~cm}$ below the response key. The chamber was located in a soundproof enclosure with a masking white noise provided by a ventilation fan. Standard solid-state programming equipment was used to control events within the box.

Procedure. The subjects were reduced to $80 \%$ of their freefeeding weight and were then fitted with opaque covers (occluders) for each eye, using a previously described technique (Stevens \& F. D. Klopfer, 1977). Habituation to the occluders was defined as an absence of head shaking and scratching and the ability to pick up single seeds with either eye covered. Following occluder habituation, each bird was trained to eat from the automated magazine, first with one eye covered and then the other. Criterion for this training was approaching the food hopper and eating within $3 \mathrm{sec}$ of operation for five consecutive presentations. When criterion performance had been achieved with one eye covered, the occluder was moved to the trained eye and the subject was magazine trained again. At the beginning of this control-eye training, the subjects were presented with five 5-sec food-hopper operations at 30 -sec intervals as a test of interocular transfer.

When magazine training had been completed for each eye, six of the subjects were trained to peck the response key with the left eye covered, the other six with the right eye covered. An autoshaping procedure was used in which, after a variable interval averaging $30 \mathrm{sec}$, the response key was illuminated for $5 \mathrm{sec}$, followed by $4 \mathrm{sec}$ access to grain. Keypecks at any time were reinforced with $4 \mathrm{sec}$ access to grain, and after five consecutive peck-produced reinforcers, the key was continuously illuminated and grain reinforcement occurred only when the bird pecked. Training was terminated after 50 peckproduced reinforcers had been earned. In the session following achievement of this criterion, a test of interocular transfer of keypeck training was made. With the control eye covered, subjects were allowed to earn 10 "warm-up" reinforcers. Then they were tested in two 20-min extinction periods. In the first period, the training eye was covered and the control eye tested, and in the second, the occluder was moved to the opposite side and the training eye was tested. The number of keypecks in each test period were recorded but no reinforcers were delivered.

\section{Results and Discussion}

None of the subjects showed any evidence of interocular transfer of magazine training during control-eye tests. Although several approached the food hopper during testing, none of them attempted to eat from it.

Similarly, there was no evidence of interocular transfer of keypecking during the extinction tests: only 3 of the 12 subjects pecked the key in the control-eye tests, whereas they all responded in the training-eye tests. Mean number of responses for the control eye was 1.0 vs. 33.4 for the training eye $[\mathrm{t}(11)=8.6, \mathrm{p}<.001]$. Comparison of the trainingeye performance failed to show a difference between those birds trained to peck with the left eye covered and those trained to peck with the right eye covered $[\mathrm{t}(10)=.51, \mathrm{p}>.5]$. To determine if the lack of responding for the control eye might be due to loss of occluder habituation, the subjects were subsequently returned to the operant chamber and given access to noncontingent magazine presentations. Regardless of which eye was covered, all of the birds demonstrated retention of magazine training by quickly approaching the magazine and eating.

Observations of the birds during the control-eye keypecking tests indicated that they oriented toward the key but did not peck at it or anything else in the chamber. It seems quite unlikely that this effect could be due to either a general inhibition of the pecking response or to a disruption of visualmotor coordination, since the birds were able to pick up individual seeds on a table top and then quickly approach the food hopper and eat during noncontingent reinforcer deliveries.

This experiment represents the first time that lack of interocular transfer of keypeck training has been shown using operant conditioning techniques. Previous operant studies have not tested for transfer of motor response training, but rather have focused on visual discrimination performance. In those studies reporting the method of keypeck training (Beale \& Williams, 1971; Catania, 1965; Corballis \& Beale, 1970; Mello, 1968; Green, Brecha, \& Gazzaniga, 1978; Tieman, Tieman, Brody, \& Hamilton, 1974), the birds were trained to keypeck binocularly before beginning monocular discrimination training. Birds trained in that manner are quite capable of keypecking with either eye covered.

\section{EXPERIMENT 2}

This experiment was designed to determine if lack of control-eye keypeck training would inhibit transfer of discrimination performance. A color discrimination task was selected in order to avoid the mirror-image reversal problem sometimes seen in transfer tests (e.g., Beale \& Corballis, 1968; Mello, 1967).

\section{Method}

Subjects. Subjects from the first experiment were divided into 
Table 1

Order of Treatment for Pigeons in Both Groups

\begin{tabular}{|c|c|c|c|}
\hline \multicolumn{2}{|c|}{ Group 1} & \multicolumn{2}{|c|}{ Group 2} \\
\hline Training Eye & Control Eye & Training Eye & Control Eye \\
\hline \multicolumn{4}{|c|}{ Experiment 1} \\
\hline Keypeck Training & \multirow[b]{2}{*}{ Keypeck Test } & Keypeck Training & \multirow[b]{2}{*}{ Keypeck Test } \\
\hline Keypeck Test & & Keypeck Test & \\
\hline \multicolumn{4}{|c|}{ Experiment 2} \\
\hline & \multirow{3}{*}{ Discrimination Test } & \multirow{2}{*}{ Discrimination Training } & Keypeck Training \\
\hline Discrimination Training & & & \\
\hline Discrimination Test & & Discrimination Training & \\
\hline Discrimination Training & Discrimination Test & Discrimination Test & \\
\hline
\end{tabular}

Table 2

Responses During a 5-Min Extinction Test Before and After Control-Eye Keypeck Training (Group 1)

\begin{tabular}{|c|c|c|c|c|c|c|c|c|}
\hline \multirow[b]{3}{*}{ Subject } & \multirow{3}{*}{$\begin{array}{c}\text { Color of } \\
\mathrm{S}+\end{array}$} & \multirow{3}{*}{$\begin{array}{c}\text { Training } \\
\text { Eye }\end{array}$} & \multicolumn{4}{|c|}{$\begin{array}{c}\text { Before Control-Eye } \\
\text { Keypeck Training }\end{array}$} & \multirow{2}{*}{\multicolumn{2}{|c|}{$\begin{array}{l}\text { After Control-Eye } \\
\text { Keypeck Training }\end{array}$}} \\
\hline & & & \multicolumn{2}{|c|}{ Training Eye } & \multicolumn{2}{|c|}{ Control Eye } & & \\
\hline & & & $S+$ & $S_{-}$ & $S+$ & S- & S+ & $\mathrm{S}-$ \\
\hline 5082 & Blue & $\mathrm{R}$ & 51 & 4 & 0 & 0 & 342 & 87 \\
\hline 5249 & Blue & $\mathbf{R}$ & 72 & 4 & 4 & 0 & 153 & 49 \\
\hline 1320 & Blue & $\mathrm{L}$ & 89 & 3 & 0 & 0 & 69 & 4 \\
\hline 1217 & Red & $\mathrm{R}$ & 87 & 0 & 0 & 0 & 120 & 11 \\
\hline 5248 & Red & $\mathrm{L}$ & 292 & 12 & 0 & 0 & 124 & 6 \\
\hline 5011 & Red & $\bar{L}$ & 107 & 0 & 0 & 0 & 74 & 4 \\
\hline
\end{tabular}

two groups, each having three birds trained to peck the key with the right eye covered and three trained with the left eye covered.

Apparatus. Discriminative stimuli visible through the response key consisted of patches of colored paper glued to a wood disk positioned $.5 \mathrm{~cm}$ behind the key surface. Stimuli visible through the key could be quickly changed by slightly rotating the disk.

Procedure. the subjects were trained on a color discrimination task with the original control eye covered. Testing of the control eye following discrimination training provided the measure of interocular transfer. The difference between groups was that birds in Group 1 received discrimination training and transfer testing before they were trained to peck the key with the control eye open, whereas birds in Group 2 received discrimination training after they were trained to peck a blank key with their control eye open (see Table 1). Control-eye keypeck training was done using the autoshaping procedure of Experiment 1.

Discrimination training. This procedure, which was the same for both groups, began with gradually changing the reinforcement schedule for keypecking to a variable-interval $30 \mathrm{sec}$ (VI 30). Next, the subjects were exposed to a red/blue discrimination task. The $\mathrm{S}+$ for half the subjects in each group was red and for the others it was blue. Pecks to $\mathrm{S}+$ were reinforced on a VI 30 -sec schedule, whereas failure to respond during the $\mathrm{S}-$ condition was reinforced after $30 \mathrm{sec}$, with each response during the $\mathrm{S}-$ condition resetting the 30 -sec delay timer. Therefore, the discriminative training procedure was a multiple VI $30-\mathrm{sec}$ DRO 30-sec schedule. The stimulus disk was moved after each reinforcer delivery, with the stimuli presented in a random (i.e., not necessarily alternating) order during the 30-min discrimination sessions. The number of responses and the cumulative time in each condition were recorded, with the criterion for discriminative performance being $90 \%$ correct responses during a single session.

Interocular transfer test. In the session following criterion performance, each subject was given a 5-min transfer test with the training eye occluded and the control eye open. During this test, the $\mathrm{S}+$ and $\mathrm{S}-$ were alternated at $30-\mathrm{sec}$ intervals, but no reinforcers were delivered. For birds in Group 1, the testing procedure was then repeated with the control eye covered and the training eye open. In the next session, Group 1 subjects were trained to peck a blank key with the training eye covered and the control eye open. Then, with the control eye covered, they were reexposed to the discrimination training procedure until criterion performance was achieved. Finally, they were given another control-eye transfer test. A 5 -min habituation period followed each occluder change.

The control-eye transfer test for Group 2 was the same as for Group 1. However, in contrast to Group 1, Group 2 showed strong transfer of conditioning. Therefore, as a control for possible transfer of extinction effects, Group 2 was reexposed to the discrimination training procedure before the training-eye discrimination test was made (see Table 1).

\section{Results and Discussion}

Group 1. There was no evidence of interocular transfer in the first control-eye tests. However, after being trained to peck a blank key with the control eye open, tests of the control eye revealed excellent discriminative performance (see Table 2).

During testing, the mean training-eye accuracy was $96.7 \%$ correct, with a range of $92.7 \%$ to $100 \%$ correct. During the first control-eye tests, none of the subjects pecked the key in either stimulus condition, except for one which made four responses to $\mathrm{S}+$. In these tests, the birds often oriented toward the key, but, as in Experiment 1, they did not peck it or anything else in the box. However, after control- 
Table 3

Responses During a 5-Min Extinction Test When Control-Eye Keypeck Training Preceded Discrimination Training (Group 2)

\begin{tabular}{ccccccrr}
\hline & \multirow{2}{*}{$\begin{array}{c}\text { Color } \\
\text { Subject }\end{array}$} & $\begin{array}{c}\text { Training } \\
\text { of S+ }\end{array}$ & Eye & \multicolumn{2}{c}{ Control Eye } & & \multicolumn{2}{c}{ Training Eye } \\
\cline { 7 - 8 } \cline { 5 - 6 } & S+ & S- & S+ & S- \\
\hline 5058 & Blue & L & 81 & 13 & 115 & 13 \\
9255 & Blue & L & 89 & 0 & 292 & 3 \\
UNB & Blue & R & 78 & 6 & 304 & 8 \\
5052 & Red & R & 192 & 15 & 184 & 13 \\
5094 & Red & R & 184 & 26 & 213 & 8 \\
805 & Red & L & 103 & 11 & 107 & 5 \\
\hline
\end{tabular}

eye keypeck training, the mean control-eye accuracy was $88.6 \%$ correct, with a range of $75.7 \%$ to $95.4 \%$. Although this represents excellent transfer of discrimination performance, the training-eye accuracy was significantly higher than the control-eye accuracy $[\mathrm{t}(5)=2.84, \mathrm{p}<.05]$.

Group 2. Control-eye testing for these subjects indicated excellent transfer of discrimination performance (see Table 3). Mean training-eye accuracy was $95.3 \%$ correct, with a range of $89.8 \%$ to $99.0 \%$. Mean control-eye accuracy was $91.7 \%$, with a range of $86.2 \%$ to $100 \%$. As in Group 1, the mean trainingeye accuracy was higher than the mean control-eye accuracy, but the Group 2 difference did not quite reach significance $[\mathrm{t}(5)=2.54, \mathrm{p}>.05]$.

\section{GENERAL DISCUSSION}

These experiments clearly show that although a visual discrimination may transfer interocularly, motor response training does not. This lack of response transfer may directly inhibit the transfer of discrimination performance; yet, after control-eye response training, discrimination performance transfers with only a minimal decrement in accuracy. That is, the discrimination transfers interocularly but the ability to demonstrate that discrimination does not transfer. Similarly Green, Brecha, and Gazzaniga (1978) found that although two stimuli could be easily distinguished by pigeons, interocular transfer of discrimination performance was controlled by the nature of the response requirement. When the task was to find and peck the $S+$, transfer was demonstrated, but when the discriminative stimuli indicated which of two keys to peck, there was no evidence of transfer.

A variety of hypotheses have been advanced concerning the environmental variables controlling the occurrence of interocular transfer, but none of them are consistent with our findings. Cherkin (1970) and Levine (1952) have suggested that the location of the discriminative stimuli (SDs) during conditioning is the critical factor: when the SDs are below the bird's head, transfer will occur, but when they are in front, transfer will not occur. However, in our first experiment the SDs were below the birds during magazine training and transfer did not occur. Similarly, in Experiment 2, when the SDs were directly in front of the birds, color discrimination performance transferred very well if there had been previous control-eye keypeck training.

Zeier (1970) proposed that transfer would occur if the task involved behaviors for which there was a "strong inherent disposition." Using that approach, we would have predicted transfer of magazine training in Experiment 1 and lack of transfer in Experiment 2.

Another possibility is that failure of transfer following occluder changes results from spacially displaced responding. This hypothesis has been advanced to account for mirror-image reversal often seen in interocular transfer tests (e.g., Beale \& Corballis, 1967; Beale \& Williams, 1971). Observation of our subjects, however, indicated that their failures to peck the response key were due to inactivity and not to misdirected responses.

We have been unable to develop our own general hypothesis to account for all or even a major portion of the available data on interocular transfer in birds. Although the results are consistent among subjects when using the same conditioning procedure, predictions for new procedures are rarely accurate. This finding strongly suggests that there may be different mechanisms functioning for each type of learning. Based on our results and those of Green, Brecha, and Gazzaniga (1978), it also seems clear that the occurrence of transfer is controlled by the nature of the response requirement and not by the discriminative stimuli used in conditioning.

At the neural level, it seems likely that nontransfer is due to memory access problems rather than a failure of transfer of visual signals. We suggest this approach because there is substantial evidence, both anatomical and electrophysiological (Perisic, Mihailovic, \& Cuenod, 1971; Robert \& Cuenod, 1969a, 1969b; Voneida \& Mello, 1975), that information from each eye is projected to both halves of the optic tectum and telencephalon via the interhemispheric commissures. Regarding memory, there is a growing body of evidence indicating that following some types of monocular conditioning, memory storage is restricted to one side of the avian brain (Bell \& Gibbs, 1977a, 1977b; Bondy \& Harrington, 1978). Benowitz (1974) has proposed that the comparatively incomplete interhemispheric connections seen in birds may make some unilateral engrams inaccessible to the side of the brain served by the control eye. If this is the case, a better understanding of interocular transfer and nontransfer must await further study of engram formation and the nature of the interhemispheric commissures. The possibility of unilateral engrams, however, offers unique oppor- 
tunities to study memory storage in one side of the brain while maintaining the other side as the control condition.

\section{REFERENCES}

Beale, I. L., \& Corballis, M. C. Laterally displaced pecking in monocularly viewing pigeons: A possible factor in interocular mirror-image reversal. Psychonomic Science, 1967, 9, 603.604.

Beale, I. L., \& Corballis, M. C. Beak shift: An explanation for interocular mirror-image reversal in pigeons. Nature, 1968 , $220,82-83$

Beale, I. L., \& Williams, R. J. Experimental control of beak shift during tests of interocular transfer of a lateral mirrorimage discrimination. Psychonomic Science, 1971, 24, 7-8.

BeLl, G. A., \& Gibis, M. E. Unilateral storage of monocular engram in day-old chick. Brain Research, 1977, 124, 263-270. (a)

BelL, G. A., \& GibBs, M. E. Interhemispheric interaction in young chickens. Proceedings of the Australian Physiological and Pharmacological Society, 1977, 8, 25. (b)

Benowitz, L. Conditioning for the bilateral transfer of monocular learning in chicks. Brain Research, 1974, 65, 203-213.

Bondy, S. C., \& Harrington, M. E. Brain blood flow: Alteration by prior exposure to a learned task. Science, 1978, 199, 318-319.

Brown, P. L., \& Jenkins, H. M. Auto-shaping of the pigeon's key-peck. Journal of the Experimental Analysis of Behavior, 1968, 11, 1-8.

Catania, C. A. Interocular transfer of discriminations in the pigeon. Journal of the Experimental Analysis of Behavior, $1965,8,147-155$.

Cheney, C. D., \& TAM, V. Interocular transfer of a line tilt discrimination without mirror-image reversal using fading in pigeons. Journal of Biological Psychology, 1972, 14, 17-20.

Cherkin, A. Eye to eye transfer of an early response modification in chicks. Nature, 1970, 227, 1153.

Corballis, M. C., \& Beale, I. L. Monocular discrimination of mirror-image obliques by pigeons: Evidence for lateralyzed stimulus control. Animal Behaviour, 1970, 18, 563-566.

Cowan, W. M., Adamson, L., \& Powell, T. P. S. An experimental study of the avian visual system. Journal of Anatomy, $1961,95,545-563$

Green, L., Brecha, N., \& Gazzaniga, M. S. Interocular transfer of simultaneous but not successive discriminations in the pigeon. Animal Learning \& Behavior, 1978, 6, 261-264.
Hearst, E., \& Jenkins, H. M. Sign-tracking: The stimulusreinforcer relation and directed action. Austin, Texas: Psychonomic Society, 1974.

KLopfen, P. H. Imprinting: Monocular and binocular cues in object discrimination. Journal of Comparative and Physiological Psychology, 1973, 84, 482-487.

LEVINE, J. Studies in the interrelations of central nervous structures in vision: III. Localization of the memory trace as evidenced by the lack of inter-and intraocular habit transfer in the pigeon. Journal of Genetic Psychology, 1952, 81, 19-27.

Melso, N. K. Inter-hemispheric comparison of visual stimuli in the pigeon. Nature, 1967, 214, 144-145.

Mello, N. K. The effect of unilateral lesions of the optic tectum on interhemispheric transfer of monocularly trained color and pattern discrimination in pigeon. Physiology \& Behavior, 1968, 3, 725-734.

Mel.lo, N. K., Ervin, F. R., \& Совв, S. Intertectal integration of visual information in pigeon: Electrophysiological and behavioral observations. Boletin del Instituto de Estudios Medicos, Biologicos Mexicanos, 1963, 21, 519-533.

Perisic, M., Mihailovic, J., \& Cuenod, M. Electrophysiology of contralateral and ipsilateral visual projections to the wulst in pigeon (Columbia livia). International Journal of Neuroscience, 1971, 2, 7-14.

PoLYaK, S. The vertebrate visual system. Chicago: University of Chicago Press, 1957.

Robert, F., \& Cuenod, M. Electrophysiology of the intertectal commissures in the pigeon. 1. Analysis of pathways. Experimental Brain Research, 1969, 9, 116-122. (a)

Robert, F., \& Cuenod, M. Electrophysiology of the intertectal commissures in the pigeon. II. Inhibitory interaction. Experimental Brain Research, 1969, 9, 123-136. (b)

Stevens, V. J., \& Klopfer, F. D. Interocular transfer of conditioning and extinction in birds. Journal of Comparative and Physiological Psychology, 1977, 91, 1074-1081.

Tieman, S. B., Tieman, D. G., Brody, B. A., \& Hamilton, C. R. Interocular reversal of up-down mirror images in pigeons. Physiology \& Behavior, 1974, 12, 615-620.

Vone IDA, T. J., \& MELLO, N. K. Interhemispheric projections of the optic tectum in pigeon. Brain Behavior and Evolution, 1975, 11, 91-108.

ZEiER, H. Lack of eye to eye transfer of an early response modification in birds. Nature, 1970, 21, 708-709.

(Received for publication November 14, 1978; revision accepted May $9,1979$. 